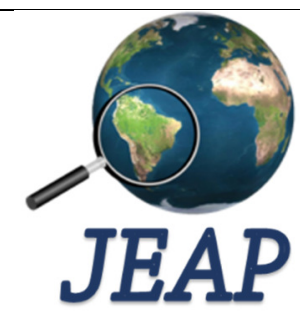

ISSN: 2525-815X

\section{Journal of Environmental} Analysis and Progress

Journal homepage: www.jeap.ufrpe.br/ http://dx.doi.org/10.24221/jeap.2.3.2017.1450.249-257

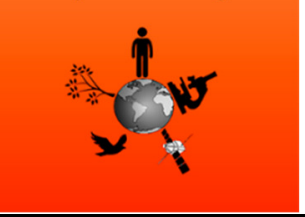

\title{
Correlação de Pearson entre pigmentos fotossintetizantes e fitomassa de plantas de Aloysia triphylla
}

\section{Pearson correlation between photosintetizant pigments and phytomass of plants of Aloysia triphylla}

Leonardo Antonio Thiesen ${ }^{\mathrm{a} *}$, Marcos Vinícius Marques Pinheiro ${ }^{\mathrm{a}}$, Evandro Holz ${ }^{\mathrm{a}}$, Daniele Cristina Fontana $^{\mathrm{a}}$, Jullie dos Santos ${ }^{\mathrm{a}}$

${ }^{a}$ Universidade Federal de Santa Maria-UFSM, Campus Frederico Westphalen, Linha 7 de Setembro, s/n, BR 386, Km 40, Frederico Westphalen-RS, Brasil. CEP: 98400-000. E-mail: thiesen07@ hotmail.com; macvini@gmail.com; evandro_holz29@hotmail.com; daani_fontana@hotmail.com; jullie27@ hotmail.com.*Autor correspondente.

A R T I C L E I N F O
Recebido 29 Jun 2017

Aceito 10 Jul 2017

Publicado 31 Jul 2017

\begin{abstract}
A B S T R A C T
The dry matter production of the crops is limited by the photosynthetic pigments, an indicator of productivity that may be restricted to the growth and development of plants. The objective of the study was to determine a correlation between photosynthetic pigments and a phytomass of Aloysia triphylla in response to different water availability. The experiment was carried out in a protected environment at the Federal University of Santa Maria, Campus Frederico Westphalen. It was conducted in a randomized block design with four treatments, four blocks and the experimental unit composed of 16 plants/block, in the period of August 28, 2015, to March 21, 2016. The treatments consisted of different levels of water availability $(100,75,50$ and $25 \%$ of the soil field capacity). They were evaluated: Chlorophyll $a$, chlorophyll $b$, carotenoids, total chlorophyll, chlorophyll $a / b$ ratio, total chlorophyll/carotenoid ratio and total dry matter, dry mass of leaves and stem. Data were submitted to Pearson's linear correlation aiming to verify the dependence of one variable on another. After 152 days, it was possible to observe that there was a high and positive correlation between chlorophyll $a$ and $b$, both of which presented a negative correlation with the chlorophyll $a / b$ ratio. Chlorophyll b showed correlation with total phytomass and leaves. It was also observed that total chlorophyll showed correlation with all variables, except for those of stem and leaf dry matter and total phytomass. It was concluded that chlorophyll $b$ presents positive correlation with dry leaf mass and total dry matter, and the leaf dry mass has a positive correlation with dry stem mass and total phytomass of A. triphylla.
\end{abstract}

Keywords: Cidró, chlorophyll, carotenoids, dry mass.

\section{R E S U M O}

A produção de matéria seca das culturas é limitada pelos pigmentos fotossintéticos, um indicador de produtividade que pode ser limitante ao crescimento e desenvolvimento das plantas. O objetivo do estudo foi determinar a correlação entre os pigmentos fotossintéticos e a fitomassa de Aloysia triphylla em resposta a diferentes disponibilidades hídrica. $\mathrm{O}$ experimento foi mantido em ambiente protegido na Universidade Federal de Santa Maria, Campus Frederico Westphalen, sendo conduzido em delineamento de blocos casualizados, com quatro tratamentos, quatro blocos e a unidade experimental composta por 16 plantas/bloco, no período de 28 de agosto de 2015 a 21 de março de 2016. Os tratamentos consistiram de diferentes níveis de disponibilidade hídrica (100, 75, 50 e $25 \%$ da capacidade de campo do solo). Foram avaliados: conteúdo de clorofila $a$, clorofila $b$, carotenoides, 
clorofila total, razão clorofila $a / b$, razão clorofila total/carotenoides e fitomassa seca total, massa seca de folhas e de caule. Para verificar a dependência de uma variável sobre outra os dados foram submetidos à correlação linear de Pearson. Após 152 dias, foi possível observar que houve correlação forte e positiva entre as clorofilas $a$ e $b$, sendo que ambas apresentaram correlação negativa com a razão clorofila $a / b$. A clorofila $b$ apresentou correlação com fitomassa total e de folhas. Também se observou que a clorofila total apresentou correlação com todas as variáveis, exceto para as de massa seca de caule e folhas e fitomassa total. Concluiu-se a clorofila $b$ apresenta correlação positiva com massa seca de folhas e fitomassa seca total, e a massa seca de folhas possui correlação positiva com massa seca de caule e fitomassa total de A. triphylla.

Palavras-Chave: Cidró, clorofila, carotenoides, massa seca.

\section{Introdução}

O Cidró (Aloysia triphylla (L’Her.) Britton, Verbenaceae) é uma planta medicinal, produtora de óleos essenciais, com propriedades digestivas, antiespasmódicas, sedativas, dentre outras, sendo também utilizada como anestésico em peixes, além de prolongar a vida útil de pescados sob refrigeração (Daniel et al., 2014).

A produção de matéria seca das culturas é limitada pelos pigmentos fotossintéticos, um indicador de produtividade que pode ser limitante ao crescimento e desenvolvimento das plantas (Dawson et al., 2003). Os pigmentos fotossintéticos (clorofila $a, b$ e carotenoides) são estruturas químicas instáveis e facilmente degradáveis, podendo alterar a qualidade e percepção luminosa dos vegetais. As plantas podem passar por condições de estresse e modificar a quantidade de pigmentos fotossintéticos, sendo que o aumento da razão de clorofila $a / b$ pode estar correlacionado à proteção do sistema fotossintético, devido a menor absorção de radiação solar (Camejo \& Torres, 2001). A determinação dos teores de pigmentos foliares é importante para compreender a resposta fisiológica das plantas em função dos diferentes manejos ou fatores ambientais que influenciam a atividade fotossintética e, consequentemente, a produtividade das culturas (Discroll et al., 2006). Geralmente, a quantificação da clorofila é determinada por métodos destrutivos, sendo necessário o preparo em solventes e posterior leitura em espectrofotômetro (Amarante et al., 2008). Entretanto, a obtenção deste parâmetro pode ser realizada mediante a utilização do clorofilômetro, que compreende um método não destrutivo (Richardson, Duigan \& Berlyn, 2002).

A correlação é uma medida de associação do grau de relacionamento entre duas variáveis (Garson, 2009) e para interpretar este grau de relação entre as variáveis, utiliza-se o coeficiente linear de Pearson, sendo que neste método os coeficientes apresentam variação de -1 a 1 , em que uma correlação é considerada forte quanto mais próximo os coeficientes estiverem de -1 ou 1
(Cargnelutti Filho et al., 2015). O objetivo do trabalho foi determinar a correlação entre os pigmentos fotossintetizantes e a fitomassa de $A$. triphylla em resposta a diferentes disponibilidades hídrica.

\section{Material e Métodos}

Material vegetal e condições do experimento

$\mathrm{O}$ estudo foi realizado na área experimental da Universidade Federal de Santa Maria, Campus Frederico Westphalen, situado a $27^{\circ} 23^{\prime} \mathrm{S}, 53^{\circ} 25^{\prime}$ O e $493 \mathrm{~m}$ de altitude, no período de 28 de agosto de 2015 a 21 de março de 2016. O clima da região é do tipo Cfa pela classificação climática de Köppen (Alvares et al., 2013). O experimento foi conduzido em ambiente protegido (estufa), com estrutura de aço galvanizado, disposta na direção Leste-Oeste, nas dimensões de 10 × $20 \mathrm{~m}$ e 3,0 m de pé direito, coberta com filme de polietileno de baixa densidade transparente com $150 \mu \mathrm{m}$ de espessura tratado contra as radiações de ultravioleta, com $87 \%$ de transmitância, sendo não seletivo.

Mudas de A. triphylla foram obtidas através da propagação vegetativa, pelo método da mini estaquia. Foram utilizadas espumas fenólicas (dimensões de $2 \times 2 \times 5 \mathrm{~cm}$ ), lavadas em água corrente para eliminação de prováveis compostos resultantes do processo de industrialização. $\mathrm{O}$ procedimento da mini estaquia consistiu da retirada de pequenas estacas com três gemas (aproximadamente $10 \mathrm{~cm}$ ) de plantas matrizes, sendo desinfestadas em solução de hipoclorito de sódio (1\% de cloro ativo) durante um minuto, e posterior lavagem em água destilada e estaqueadas em espuma fenólica. Utilizou-se uma célula da espuma fenólica para cada mini estaca, introduzindo-se um nó no substrato e dois fora da espuma.

Para o pegamento das mini estacas, as placas de espuma fenólica foram deixadas sobre bancada com subirrigação constante, na forma de lâmina de água, sendo os turnos de rega controlados através de timer com 15 minutos ligados e 60 minutos desligados. No período 
noturno realizou-se apenas dois períodos de irrigação de 15 minutos. A água utilizada para a irrigação foi armazenada em reservatório de 40 litros e, após ser bombeada e passar pela espuma fenólica, retornava para o recipiente. Após 13 dias nestas condições, a água foi substituída por $25 \%$ de solução nutritiva indicada por Furlani (2009). A condutividade elétrica e o $\mathrm{pH}$ da solução foram mantidos em, aproximadamente, $300 \mu \mathrm{S}$ e 6 , respectivamente.

Após 68 dias, as miniestacas foram transplantadas para vasos de cinco litros contendo substrato comercial Carolina $^{\circledR}$, para a perfeita formação das mudas, durante mais 84 dias. Para a condução do experimento, mudas de 152 dias foram transplantadas para vasos de capacidade de 14 litros, preenchidos com uma fina camada de brita (3 kg) e uma mistura de substrato (solo peneirado e $10 \%$ de esterco bovino curtido). Para evitar perda excessiva de água pelo processo de evapotranspiração, foram adicionados bagaço de cana-de-açúcar na proporção de 100 gramas em cada vaso, com o intuito de formar a cobertura de solo. Para promover a maior reflexão e menor absorção da radiação solar, os vasos foram pintados de branco na parte exterior, para evitar o superaquecimento e a perda excessiva de água pelo processo de evaporação do solo.

\section{Delineamento experimental e disponibilidade hídrica}

$\mathrm{O}$ experimento foi conduzido em delineamento de blocos casualizado, com quatro tratamentos, quatro blocos, sendo cada bloco composto por 16 plantas. Os tratamentos consistiram em diferentes níveis de disponibilidade hídrica: 100, 75, 50 e 25\% da capacidade de campo. Iniciou-se a restrição hídrica aos 45 dias antes da coleta das plantas para avaliação, ou seja, a partir do período que corresponde à metade da estação de verão. Antes do início da restrição hídrica, realizou-se as irrigações até o solo atingir $100 \%$ da capacidade de campo.

Para a manutenção do controle da disponibilidade hídrica, realizou-se a pesagem dos vasos, com balança digital de capacidade máxima de $40 \mathrm{~kg}$, diariamente. A reposição da água evapotranspirada foi realizada sempre que a variação entre a massa inicial do vaso e a massa obtida no dia da avaliação tornava-se igual ou superior a $2 \%$. Assim, a diferença entre as massas correspondia à quantidade de água a ser completada.

\section{Variáveis analisadas}

Após 45 dias de início do experimento com restrição hídrica, foram analisadas as seguintes variáveis: clorofila $a$ (ChlLOG $a$ ), clorofila $b$ (ChlLOG $b$ ), clorofila total $(a+b)$, razão clorofila $a / b($ ChlLOG $a / b)$, quantificados pelo método não destrutivo; clorofila $a(\mathrm{Chl} a)$, clorofila $b(\mathrm{Chl} b)$, carotenoides, clorofila total $(a+b)$, razão clorofila $a / b \quad(\mathrm{Chl} a / b), \quad$ clorofila total/carotenoides $(a+b /$ carotenoides $)$, quantificados pelo método destrutivo; massa seca de folhas (MSF), massa seca de caule (MSC) e fitomassa seca total (FST). A fitomassa seca total corresponde à soma da massa seca do caule e massa seca das folhas.

Os pigmentos fotossintéticos foram avaliados e determinados de duas maneiras: por métodos destrutivos e não destrutivos. $\mathrm{O}$ método não destrutivo consistiu da medição do teor de clorofila através de clorofilômetro digital (ClorofiLOG ${ }^{\circledR}$ modelo CFL 1030). As amostragens foram retiradas do quarto nó do ápice em direção à base do maior ramo da planta, retirando-se três repetições por planta, totalizando 48 amostras por tratamento, sendo realizado média por planta. $\mathrm{O}$ ClorofiLOG ${ }^{\circledR}$ é um método rápido, porém realiza a determinação apenas das clorofilas $a$ e $b$. Este equipamento mede a quantidade de radiação transmitida através das folhas, de forma óptica e em diferentes comprimentos de onda, sendo dois na faixa do vermelho, próximos aos picos de absorção da clorofila, e um próximo do infravermelho (Tonin et al., 2016).

Para quantificação dos pigmentos fotossintéticos (clorofila $a, b$ e carotenoides), pelo método destrutivo, foram utilizados discos foliares das folhas localizadas no quarto nó do ápice em direção à base do maior ramo, de todas as plantas. Foram retirados cinco discos foliares de material fresco, de 5,0 $\mathrm{mm}$ de diâmetro e transferidos para tubos de ensaio com $5,0 \mathrm{~mL}$ de solução de dimetilsulfóxido - DMSO (saturado com 5,0 g.L $\mathrm{L}^{-1}$ de carbonato de cálcio, $\mathrm{CaCO}_{3}$ ), seguindo a metodologia proposta por Santos et al. (2008). Os discos permaneceram incubados durante um período de 48 horas, cobertos com papel alumínio e mantidos em local escuro. Após 48 horas, determinou-se a absorbância das amostras em espectrofotômetro BEL Photonics, modelo SP acios 1105 , utilizando-se cubetas de vidro com 10 $\mathrm{mm}$ de caminho óptico, nos comprimentos de onda de 645,665 e $480 \mathrm{~nm}$, para clorofila $a, b$ e carotenoides, respectivamente. Os cálculos (em mg de clorofila por g de massa fresca de tecido foliar) foram realizados seguindo a metodologia descrita por Hiscox \& Israelstam (1979):

(1) Clorofila $a=\{[(11,75 *$ A665 $-(2,35 *$ A645) ] $* 50\} / 500$ 
(2) Clorofila $b=\{[(18,61 * \mathrm{~A} 645)-(3,96 *$ $\mathrm{A} 665)] * 50\} / 500$

(3) Carotenoides $=\{[\{[(1000 * \mathrm{~A} 480)-(2,27 *$ $\mathrm{Ca})-(81,4 * \mathrm{Cb})] / 227\}] * 50\} / 50$

A clorofila total $(a+b)$ foi determinada pelo somatório da clorofila $a$ com clorofila $b$; a razão $a / b$, pela divisão da clorofila $a$ pela clorofila $b$; e clorofila total/carotenoides, sendo calculada pela soma das clorofilas $a$ e $b$ e posterior divisão pelos carotenoides. Para determinação dos valores de massa seca de folhas e de caule, as plantas foram mantidas em estufa de secagem com temperatura de, aproximadamente $60^{\circ} \mathrm{C}$, até atingirem massa seca constante, sendo posteriormente pesadas em balança de precisão.

\section{Análise estatística}

Os dados foram submetidos à análise de variância e, para verificar as dependências e associações entre as variáveis analisadas, os dados foram submetidos à correção linear de Pearson (r). Utilizou-se o programa estatístico SAS (Statistical Analysis System). O grau de correlação entre as variáveis foi classificado pelos valores dos coeficientes de correlação [ $\mathrm{r}=0,10$ até 0,30 (fraco); $\mathrm{r}=0,40$ até 0,6 (moderado); $\mathrm{r}=0,70$ até 1 (forte)], segundo Dancey \& Reidy (2006).

\section{Resultados}

A análise de variância permitiu observar que houve significância $(\mathrm{p}<0,05)$ para as variáveis clorofila $a$ e razão $a / b$, clorofila total (obtidos pelo método destrutivo), massa seca de caule, massa seca de folhas e fitomassa seca total, com as variáveis clorofila $a$, clorofila $b$ e razão clorofila $a / b$ (obtidas pelo método não destrutivo); e clorofila $b$, carotenoides e razão clorofila total/carotenoides (obtidos pelo método destrutivo) não apresentando diferença significativa $(\mathrm{p}>0,05)$ (Tabela 1).

Tabela 1. Resumo da análise de variância para os parâmetros clorofila $a$, clorofila $b$, razão clorofila $a / b$ (ChlLOG $a$, ChlLOG $b$, ChlLOG $a / b$, respectivamente; pelo método não destrutivo); clorofila $a$ (Chl $a$ ), clorofila $b(\mathrm{Chl} b)$, carotenoides, clorofila total $(\mathrm{Chl} a+b)$, razão clorofila $a / b(\mathrm{Chl} a / b)$, clorofila total/carotenoides [ $(a+b) /$ caro], obtidos pela método destrutivo, e massa seca de folhas (MSF), massa seca de caule (MSC) e fitomassa seca total (FST) de Aloysia triphylla quando submetidas à diferentes disponibilidades hídricas. Frederico Westphalen, RS, 2017.

\begin{tabular}{|c|c|c|c|c|c|c|c|}
\hline \multirow[b]{2}{*}{ FV } & \multirow[b]{2}{*}{ GL } & \multicolumn{6}{|c|}{ Quadrados Médios } \\
\hline & & $\begin{array}{c}\text { ChILOG } \\
a\end{array}$ & $\begin{array}{c}\text { ChILOG } \\
b\end{array}$ & $\begin{array}{c}\text { ChlLOG } \\
a / b\end{array}$ & Chl $a$ & Chl $b$ & Carotenoides \\
\hline Tratamento & 3 & $2152^{\mathrm{ns}}$ & $492,51^{\mathrm{ns}}$ & $0,57^{\mathrm{ns}}$ & $54,46^{*}$ & $3,9^{\mathrm{ns}}$ & $3,81^{\mathrm{ns}}$ \\
\hline Bloco & 3 & $583,3^{\text {ns }}$ & $183,07^{\mathrm{ns}}$ & $0,51^{\mathrm{ns}}$ & $10,7^{\mathrm{ns}}$ & $4,23^{\mathrm{ns}}$ & $1,12^{\mathrm{ns}}$ \\
\hline Resíduo & 57 & $1952,58^{\mathrm{ns}}$ & $305,26^{\mathrm{ns}}$ & $0,32^{\mathrm{ns}}$ & $12,7^{\mathrm{ns}}$ & $2,03^{\mathrm{ns}}$ & $1,37^{\mathrm{ns}}$ \\
\hline $\mathrm{CV}(\%)$ & & 15,38 & 23,57 & 14,13 & 18,95 & 49,76 & 22,34 \\
\hline \multirow{2}{*}{ FV } & \multirow{2}{*}{ GL } & \multicolumn{6}{|c|}{ Quadrados Médios } \\
\hline & & Chl $a+b$ & $(a+b) /$ caro & Chl $a / b$ & MSC & MSF & FST \\
\hline Tratamento & 3 & $73,05^{*}$ & $0,66^{\mathrm{ns}}$ & $58,98 *$ & $164,76^{*}$ & $687,08 *$ & $1167,67 *$ \\
\hline Bloco & 3 & $7,39^{\mathrm{ns}}$ & $1,26^{\mathrm{ns}}$ & $28,87^{\text {ns }}$ & $116,74^{\mathrm{ns}}$ & $105,35^{\mathrm{ns}}$ & $514,59 *$ \\
\hline Resíduo & 57 & $14,6^{\mathrm{ns}}$ & $0,87^{\mathrm{ns}}$ & $16,69^{\text {ns }}$ & $47,81^{\text {ns }}$ & $38,12^{\mathrm{ns}}$ & $100,78^{\mathrm{ns}}$ \\
\hline $\mathrm{CV}(\%)$ & & 17,64 & 21,92 & 50,44 & 20,28 & 30,87 & 18,86 \\
\hline
\end{tabular}

FV = Fonte de variação; GL = Graus de liberdade; $*$ = Significativo a 5\% de probabilidade de erro; ${ }^{\text {ns }}=$ Não significativo; $\mathrm{CV}=$ Coeficiente de variação.

Foi possível verificar que houve correlação significativa entre as variáveis clorofila $a$, clorofila $b$ e razão clorofila $a / b$, obtidas a partir do método não destrutivo. Já dentre as clorofilas obtidas pelo método destrutivo, a clorofila $b$ apresentou correlação significativa quando comparado a razão clorofila $a / b$, clorofila total $\mathrm{e}$ clorofila total/carotenoides. A clorofila $a$, obtida pelo mesmo método, apresentou correlação significativa com carotenoides e clorofila total.
Além disso, foi possível observar que houve correlação significativa entre as clorofilas obtidas pelos diferentes métodos de medição, como é o caso da clorofila $a$ (ChlLOG $a$ ) que apresentou correlação significativa com clorofila $a$, clorofila $b$ e razão $a / b$ obtidas pelo método destrutivo. Os carotenoides apresentaram correlação significativa com as clorofilas (exceto para $\mathrm{Chl} b$ ), clorofila total e clorofila total/carotenoides. A clorofila total apresentou correlação significativa com todas as 
variáveis analisadas, exceto para as variáveis de fitomassa seca total e massa seca de folha e de caule. Por sua vez, a variável fitomassa seca total, apresentou correlação significativa quando comparada a variável clorofila $b$ (ChlLOG $b$ ), razão clorofila $a / b(\mathrm{Chl} a / b)$, massa seca de caule e massa seca de folhas. Já para massa seca de folhas, foi possível observar correlação significativa quando comparada a fitomassa seca total, massa seca de caule, e a razão de clorofila $a / b$ (ChlLOG $a / b)$ (Tabela 2).

Tabela 2. Análise da correlação linear de Pearson entre os parâmetros clorofila $a$ (ChlLOG $a$ ), clorofila $b$ (ChlLOG $b$ ), razão clorofila $a / b$ (ChlLOG $a / b$ ), obtidas a partir do método não destrutivo (ClorofiLOG ${ }^{\circledR}$ ); clorofila $a(\mathrm{Chl} a)$, clorofila $b(\mathrm{Chl} b)$, carotenoides, clorofila total $(\mathrm{Chl} a+b)$, razão clorofila $a / b(\mathrm{Chl} a / b)$, clorofila total/carotenoides $[(a+b) /$ caro] obtidas pelo método destrutivo, e massa seca de folhas (MSF), massa seca de caule (MSC) e fitomassa seca total (FST) de Aloysia triphylla quando submetidas à diferentes disponibilidades hídricas. Frederico Westphalen, RS, 2017.

\begin{tabular}{|c|c|c|c|c|c|c|}
\hline Variáveis & $\begin{array}{c}\text { ChILOG } \\
a \\
\end{array}$ & $\begin{array}{c}\text { ChlLOG } \\
b \\
\end{array}$ & $\begin{array}{c}\text { ChlLOG } \\
a / b \\
\end{array}$ & Chl $a$ & Chl $b$ & Carotenoides \\
\hline ChlLOG $a$ & 1 & $0,856^{*}$ & $-0,585^{*}$ & $0,598 *$ & $0,233^{\mathrm{ns}}$ & $0,435^{*}$ \\
\hline ChlLOG $b$ & & 1 & $-0,807^{*}$ & $0,633 *$ & $0,210^{\mathrm{ns}}$ & $0,491 *$ \\
\hline ChlLOG $a / b$ & & & 1 & $-0,649 *$ & $-0,100^{\mathrm{ns}}$ & $-0,540 *$ \\
\hline Chl $a$ & & & & 1 & $0,020^{\mathrm{ns}}$ & $0,732 *$ \\
\hline Chl $b$ & & & & & 1 & $-0,140^{\mathrm{ns}}$ \\
\hline Carotenoides & & & & & & 1 \\
\hline Variáveis & Chl $a+b$ & Chl $a / b$ & $(a+b) / c a r o$ & MSF & MSC & FST \\
\hline ChlLOG $a$ & $0,638^{*}$ & $-0,209^{\text {ns }}$ & $0,152^{\text {ns }}$ & $0,232^{\mathrm{ns}}$ & $0,205^{\mathrm{ns}}$ & $0,208^{\mathrm{ns}}$ \\
\hline ChlLOG $b$ & $0,661^{*}$ & $-0,220^{*}$ & $0,096^{\text {ns }}$ & $0,352 *$ & $0,242^{\mathrm{ns}}$ & $0,258 *$ \\
\hline ChlLOG $a / b$ & $-0,637^{*}$ & $0,276^{*}$ & $-0,006^{\mathrm{ns}}$ & $-0,305^{*}$ & $-0,087^{\mathrm{ns}}$ & $-0,181^{\mathrm{ns}}$ \\
\hline Chl $a$ & $0,933 *$ & $-0,130^{\mathrm{ns}}$ & $0,049^{\mathrm{ns}}$ & $0,088^{\mathrm{ns}}$ & $0,106^{\mathrm{ns}}$ & $0,043^{\text {ns }}$ \\
\hline Chl $b$ & $0,380^{*}$ & $-0,612 *$ & $0,569 *$ & $0,250^{\mathrm{ns}}$ & $0,077^{\mathrm{ns}}$ & $0,194^{\text {ns }}$ \\
\hline Carotenoides & $0,627^{*}$ & $-0,158^{\text {ns }}$ & $-0,578^{*}$ & $0,093^{\text {ns }}$ & $0,087^{\mathrm{ns}}$ & $0,047^{\text {ns }}$ \\
\hline Chl $a+b$ & 1 & $-0,331^{*}$ & $0,251^{*}$ & $0,172^{\mathrm{ns}}$ & $0,126^{\mathrm{ns}}$ & $0,111^{\mathrm{ns}}$ \\
\hline Chl $a / b$ & & 1 & $-0,157^{\mathrm{ns}}$ & $-0,374 *$ & $-0,153^{\mathrm{ns}}$ & $-0,318^{*}$ \\
\hline$(a+b) /$ caro & & & 1 & $0,077^{\mathrm{ns}}$ & $0,012^{\mathrm{ns}}$ & $0,065^{\text {ns }}$ \\
\hline MSF & & & & 1 & $0,679 *$ & $0,918^{*}$ \\
\hline MSC & & & & & 1 & $0,915^{*}$ \\
\hline FST & & & & & & 1 \\
\hline
\end{tabular}

* Significativo a 5\% de probabilidade. ${ }^{\text {ns }}$ Não significativo.

Houve correlação forte e positiva entre clorofila $a$ e $b(0,856)$, no qual pode-se inferir que o aumento do conteúdo de pigmento de uma clorofila estar associado ao aumento da outra. Foi possível observar correlação negativa entre as clorofilas $a$ e $b$ e a razão clorofila $a / b(-0,585$ e 0,807 , respectivamente), sendo que a clorofila $b$ apresentou correlação negativa forte. Houve também correlação negativa moderada observada entre a clorofila $b$ e a razão $a / b(-0,612)$.

A clorofila total $(\mathrm{Chl} a+b)$ apresentou correlação para a maioria das variáveis, exceto para as variáveis massa seca de caule, massa seca de folhas e fitomassa seca total. Para clorofila total $($ Chl $a+b)$, foi possível observar correlação forte com a variável clorofila $a(0,933)$ pelo método destrutivo, enquanto para clorofilas (ChILOG $a$ e ChlLOG $b$ ) e carotenoides ocorreu correlação moderada positiva comparada com clorofila total. Ainda para clorofila total, observou-se correlação moderada negativa com razão $a / b(-0,637)$, sendo que, para as demais, houve correlação fraca.

Os carotenoides apresentaram correlação moderada quando comparado as clorofilas $a$ (ChlLOG $a$ ), clorofila $b$ (ChlLOG $b$ ) e total (Chl $a+b)$ com coeficientes de correlação de 0,435 ; 0,491 e 0,627, respectivamente. Além disso, também se observou correlação negativa entre os carotenoides e a razão entre clorofila total/carotenoides $(-0,578)$. A razão clorofila total/carotenoides também mostrou correlação 
positiva fraca para clorofila total $(\mathrm{Chl} a+b)$ de 0,251 e moderada para clorofila $b(\mathrm{Chl} b)$ de 0,569 .

Para a variável massa seca das folhas, foi possível observar correlação moderada positiva quando comparada a massa seca do caule $(0,679)$. Observou-se correlação forte e positiva para a massa seca de folhas e de caule quando comparadas a fitomassa seca total $(0,918$ e 0,915 , respectivamente). Além disso, a massa seca de folhas e fitomassa seca total apresentaram correlação positiva fraca quando comparadas à clorofila $b$ (ChlLOG $b$ ) com coeficientes de 0,352 e 0,258 , respectivamente.

\section{Discussão}

Observou-se que os resultados obtidos entre os diferentes métodos de determinação dos teores de clorofila (método destrutivo ou não destrutivo) apresentaram semelhanças, confirmando que o equipamento ClorofiLOG $^{\circledR}$ pode ser recomendado para determinação das clorofilas, porém com menor precisão do que quando comparado ao método de extração de pigmentos, pois esta extrai a clorofila dos discos através de solventes e é determinada por espectrofotometria. Argenta et al. (2001), concluíram que para avaliações de nitrogênio em milho, a utilização de clorofilômetro em estádios iniciais não é muito preciso, porém apresenta vantagens como o baixo custo e rapidez na determinação dos conteúdos de clorofila. A correlação negativa moderada, observada entre a clorofila $b$ e a razão $a / b$, demonstra a dependência de uma variável a outra, pois a medida que ocorre aumento da clorofila $b$, tem-se uma redução da razão $a / b$. O mesmo foi observado por Lakshmi, Vanangamudi \& Thandapani (2011), no qual observaram que o incremento no conteúdo de clorofila $b$ promoveu redução de clorofila $a / b$.

$\mathrm{O}$ crescimento e adaptação das plantas a determinados ambientes estão associados aos teores de clorofila. As clorofilas presentes nas folhas são responsáveis pela absorção e transferência da energia luminosa até os centros de reação, sendo que é fundamental o perfeito funcionamento deste sistema; pois a composição do conteúdo dos pigmentos fotossintéticos (clorofila $a$, clorofila $b$ e carotenoides) afetam diretamente a taxa fotossintética das folhas (Stenbaek \& Jensen, 2010). Uma planta com altos teores de clorofila apresenta a capacidade de atingir elevadas taxas fotossintéticas (Almeida et al., 2004; Porra, Thompson \& Kridemann, 1989; Chappelle \& Kim, 1992). Portanto, as concentrações dos pigmentos fotossintéticos demonstram o estado de funcionamento do aparelho fotossintético das plantas (Alvarez et al., 2012).

No presente estudo, a correlação positiva entre as clorofilas demonstra que estes pigmentos fotossintéticos são importantes para absorção da energia luminosa, transformação em energia química e conversão desta energia em fotoassimilados, importantes para o crescimento e desenvolvimento das plantas. Quando as plantas são submetidas à estresse hídrico, a composição de clorofila tem impacto positivo na capacidade de superação à estas condições (O' Neill, Shanahan \& Schepers, 2006). Discroll et al. (2006) relatam que a quantificação de clorofila $a, b$ e total é importante para compreender a atividade fotossintética das plantas, quando estas se encontram em diferentes condições no ambiente de produção. Com isso, a correlação demonstra que as clorofilas são dependentes uma da outra, e que a atividade fotossintética vai depender do grau de associação e das condições ambientais em que as plantas estão submetidas.

Os carotenoides são moléculas que também auxiliam no processo de absorção de luz e apresentam correlação positiva com as clorofilas, demonstrando que o incremento de uma, influencia positivamente o aumento da outra. Os carotenoides são pigmentos acessórios que além de estarem associados às moléculas de clorofila e contribuir para promoção da coloração dos tecidos vegetais, desempenham papel essencial na fotoproteção, evitando danos ocasionados pelo excesso de radiação solar, que promovem excitação das moléculas de clorofila (Taiz et al., 2017). Ainda de acordo com os mesmos autores, o mecanismo de fotoproteção atua como uma válvula de segurança, liberando o excesso de energia antes que ocorra danos ao organismo vegetal. Streit et al. (2005) salientaram que os pigmentos clorofilianos estão presentes nas mais diversas espécies vegetais, porém, as diferenças na coloração entre os vegetais podem ser justificadas pela presença dos carotenoides, no qual acompanham as clorofilas (Von Elbe, 2000). Portanto, a correlação obtida entre os pigmentos (clorofilas e carotenoides), demonstra que ambos atuam concomitantemente nas plantas, em que além de determinar a pigmentação destas, são responsáveis pela absorção da radiação solar durante as reações luminosas da fotossíntese para produção de energia aos vegetais.

A correlação moderada apresentada entre massa seca de folhas e massa seca de caule devese ao aumento do caule também influenciar positivamente a quantidade de gemas vegetativas e assim, a emissão de folhas. A produção de massa seca de plantas refere-se ao resultado da fixação de 
carbono obtido a partir do processo fotossintético (Duarte \& Peil, 2010). Assim, a distribuição da matéria seca entre os órgãos da planta está relacionada ao metabolismo e fluxo de fotoassimilados, que são governados pelo sistema fonte-dreno.

$\mathrm{O}$ incremento de massa seca nas plantas coincide com o aumento de área foliar e teor de clorofila, sendo que plantas quando cultivadas em condições de estresse, podem apresentar mais clorofila (Ilic et al., 2015), isso por que, em condições de estresse, as plantas reduzem a taxa fotossintética, o fechamento estomático, além de reduzir a biossíntese de clorofila (Rhein et al., 2015) e, em condições de diferentes disponibilidade hídrica, reduz o crescimento (Flowers \& Colmer, 2008; Santos et al., 2013). Porém, no presente trabalho apenas os teores de clorofila $b$ apresentaram correlação significativa (fraca) com massa seca de folhas e fitomassa seca total. O aumento da clorofila $b$ pode ser uma resposta adaptativa da planta, pois esta clorofila capta energia de outros comprimentos de onda e transfere para clorofila $a$ para ser utilizada nas reações luminosas durante $o$ processo fotossintético (Engel \& Poggiani, 1991). Ainda, a clorofila $b$ possui degradação mais lenta do que a clorofila $a$, o que torna este o mecanismo de absorção de luz mais eficiente, quando às plantas estão submetidas a condições ambientais desfavoráveis.

Portanto, a correlação permite inferir sobre a resposta que uma variável exerce sobre outra. Segundo Olivoto et al. (2016), o conhecimento do grau de associação entre as características de plantas é fundamental para programas de melhoramento genético. Além disso, salientam que o método de correlação linear possibilita verificar os efeitos diretos e indiretos que um grupo de variáveis exercem sobre uma resposta ou variável de interesse. Quando as plantas se encontram submetidas às condições de déficit hídrico, ocorre desidratação celular, o que pode afetar muitos outros processos fisiológicos das plantas, como: redução da turgidez das células; ocorre concentração de íons, tornando-se citotóxicos; e acúmulo de ácido abscísico (ABA), o que promove o fechamento estomático, reduz as trocas gasosas, e assim, influenciando no funcionamento adequado das clorofilas e assim, inibição da fotossíntese (Taiz et al., 2017).

Ainda, no caso de plantas medicinais, produtoras de óleos essenciais, como no caso da $A$. triphylla, o déficit hídrico pode provocar alterações na produção e na composição química do óleo essencial. Isso por que, quando as plantas se encontram em condições de estresse, tendem a apresentar maior quantidade de glândulas oleosas e assim produzir maior quantidade de óleo por planta (Leal et al., 2001). Devido à importância e aplicabilidade do óleo essencial de A. triphylla, futuros estudos são fundamentais para correlacionar a produção e qualidade do óleo essencial com as condições ambientais em que às plantas estão submetidas, capazes de influenciar as características morfofisiológicas das plantas.

\section{Conclusão}

As clorofilas $a$ e $b$ possuem correlação negativa com a relação de clorofila $a / b$.

A clorofila $b$ apresenta correlação positiva com massa seca de folhas e fitomassa seca total em condições de diferentes disponibilidades hídricas.

A massa seca de folhas de Aloysia triphylla possui correlação positiva com massa seca de caule e fitomassa seca total das plantas.

Os processos fotossintéticos são dependentes dos conteúdos de clorofila, que influenciam diretamente no crescimento e desenvolvimento vegetal.

\section{Agradecimentos}

À Coordenação de Aperfeiçoamento de Pessoal de Nível Superior-Capes e ao Conselho Nacional de Desenvolvimento Científico e Tecnológico-CNPq pela concessão de bolsas de estudos.

\section{Referências}

ALMEIDA, L. P.; ALVARENGA, A. A.; CASTRO, E. M.; ZANELA, S. M.; VIEIRA, C. V. 2013. Crescimento inicial de plantas de Cryptocaria aschersoniana Mez. submetidas a níveis de radiação solar. Ciência Rural, v. 34, n. 1, p. 83-88.

ALVARES, C. A.; STAPE, J. L.; SENTELHAS, P. C.; DE MORAES, G.; LEONARDO, J.; SPAROVEK, G. 2013. Köppen's climate classification map for Brazil. Meteorologische Zeitschrift, v. 22, n. 6, p. 711-728.

ALVAREZ, C.; SÁEZ, P.; SÁEZ, K.; SÁNCHEZOLATE, M.; RÍOS, D. 2012. Effects of light and ventilation on physiological parameters during in vitro acclimatization of Gevuina avellana mol. Plant Cell, Tissue and Organ Culture, v. 110, p. 93101.

AMARANTE, C. V. T.; STEFFENS, C. A.; ZANARDI, O. Z.; ALVES, E. de O. 2008. Quantificação de clorofilas em folhas de macieiras 'Royal Gala' e 'Fuji' com métodos ópticos não- 
destrutivos. Revista Brasileira de Fruticultura, v. 30, n. 3, p. 590-595.

ARGENTA, G., SILVA, P. R. F. D., BORTOLINI, C. G., FORSTHOFER, E. L., STRIEDER, M. L. 2001. Relationship of reading of portable chlorophyll meter with contents of extractable chlorophyll and leaf nitrogen in maize. Revista Brasileira de Fisiologia Vegetal, v. 13, n. 2, p. 158167.

CAMEJO, D.; TORRES, W. 2001. High temperature effect on tomato (Lycopersicon esculentum) pigment and protein content and cellular viability. Cultivos Tropicales, v. 22, n. 3, p. 13-17.

CARGNELUTTI FILHO, A.; TOEBE, M.; ALVES, B. M.; BURIN, C.; SANTOS, G. O.; FACCO, G.; NEU, I. M. M. 2015. Relações lineares entre caracteres de aveia preta. Ciência Rural, v.45, n.6, p.985-992.

CHAPPELLE, E. W.; KIM, M. S. 1992. Ratio analysis of reflectance spectra (RARS): an algorithm for a remote estimation of the concentractions of clorophyll A, chorophyll B, and carotenoids in soybean leaves. Remote Sensing of Environment, v. 39, n. 3, p. 239-247.

DANCEY, C.; REIDY, J. 2006. Estatística Sem Matemática para Psicologia: Usando SPSS para Windows. Porto Alegre, Artmed.

DANIEL, A. P.; VEECK, A. P. L.; KLEIN, B.; FERREIRA, L. F.; CUNHA, M. A.; PARODI, T. V.; ZEPPENFELD, C. C.; SCHMIDT, D.; CARON, B. O.; HEINZMANN, B. M.; BALDISSEROTTO, B.; EMANUELLI, T. 2014. Using the essential oil of Aloysia triphylla (L'Her.) Britton to sedate silver catfish (Rhamdia quelen) during transport improves the chemical and sensory qualities of the fish during storage in ice. Journal of Food Science, v. 79, n. 6, p. 1205-1211.

DAWSON, T. P.; NORTH, P. R. J.; PLUMMER, S. E.; CURRAN, P. J. 2003. Forest ecosystem chlorophyll content: implications for remotely sensed estimates of net primary productivity. International Journal of Remote Sensing, v. 24, n. 3, p. 611-617.

DRISCOLL, S. P.; PRINS, A.; OLMOS, E.; KUNERT, K. J.; FOYER, C. H. 2006. Specification of adaxial and abaxial stomata, epidermal structure and photosynthesis to $\mathrm{CO}_{2}$ enrichment in maize leaves. Journal of Experimental Botany, v. 57, n. 2, p. 381-390.

DUARTE, T. S.; PEIL, R. M. N. 2010. Relações fonte: dreno e crescimento vegetativo do meloeiro. Horticultura Brasileira, v. 28, n. 3, p. 271-276.

ENGEL, V. L.; POGGIANI, F. 1991. Estudo da concentração de clorofila nas folhas e no espectro de luz em função do sombreamento em mudas de quatro espécies florestais nativas. Revista Brasileira de Fisiologia Vegetal, v. 3, n. 1, p. 3945.

FLOWERS, T. J.; COLMER, T. D. 2008. Salinity tolerance in halophytes. New Phytologist, v. 179, n. 4 , p. $945-963$.

FURLANI, P. R. 2009. Cultivo de frutas e hortaliças em ambiente protegido. Fortaleza: Instituto Frutal, 37p.

GARSON, G. D. 2009. Statnotes: Topics in Multivariate Analysis. Disponível em: http://faculty.chass.ncsu.edu/garson/PA765/statno te.htm. Acesso em: 28 de abril de 2017.

HISCOX, J. D.; ISRAELSTAM, G. F. 1979. A method for the extraction of chlorophyll from leaf tissue without maceration. Canadian Journal of Botany, v. 57, n. 12, p. 1332-1334.

ILIC，Z. S.; MILENKOVIC，L.; SUNIC，L.; FALLIK, E. 2015. Effect of coloured shade-nets on plant leaf parameters and tomato fruit quality. Science of Food and Agriculture, v. 95, n. 13, p. 2660-2667.

LAKSHMI, P. M.; VANANGAMUDI, M.; THANDAPANI, V. 2011. Effects of low light on yield and physiological attributes of rice. International Rice Research Notes, v. 29, n. 2, p. 71-73.

LEAL, T. C. A. D. B.; DE PAIVA FREITAS, S.; DA SILVA, J. F.; DE CARVALHO, A. J. C. 2001. Avaliação do efeito da variação estacional e horário de colheita sobre o teor foliar de óleo essencial do capim-cidreira (Cymbopogoncitratus (DC) Stapf). Revista Ceres, v. 48, n. 278, p. 445453.

O'NEILL, P. M.; SHANAHAN, J. F.; SCHEPERS, J. S. 2006. Use of chlorophyll fluorescence assessments to differentiate corn hybrid response to variable water conditions. Crop 
Science, v. 46, n. 2, p. 681-687.

OLIVOTO, T.; NARDINO, M.; CARVALHO, I. R. C.; FOLLMANN, D. N.; SZARESKI, V. J.; FERRARI, M.; PELEGRIN, A. L.; SOUZA, V. 2016. Pearson correlation coefficient and accuracy of path analysis used in maize breeding: a critical review. International Journal of Current Research, v. 8 , n. 9 , p. $37787-37795$.

PORRA, R. J.; THOMPSON, W. A.; KRIDEMANN, P. E. 1989. Determination of accurate extinction coefficients and simultaneous equations for assaying $a$ and $b$ extracted with four different solvents: verification of the concentration of chorophylls standards by atomic absorption spectroscopy. Biochimic et Biophysic Acta, v. 975, n. 3, p. 384-394.

RHEIN, A. F. L.; CRUZ, F. J. R.; FERRAZ, R. L. S.; SANTOS, D. M. M. 2015. Crescimento radicular e pigmentos clorofilianos em duas forrageiras submetidas a níveis crescentes de $\mathrm{NaCl}$. Científica, v.43, n.4, p.330-335.

RICHARDSON, A. D.; DUIGAN, S. P.; BERLYN, G. P. 2002. An evaluation of noninvasive methods to estimate foliar chlorophyll content. New Phytologist, v. 153, n. 1, p. 185-194.

SANTOS, R. P.; CRUZ, A. C. F. D.; IAREMA, L.; KUKI, K. N.; OTONI, W. C. 2008. Protocolo para extração de pigmentos foliares em porta-enxertos de videira micropropagados. Revista Ceres, v. 55, n. 4 , p. 356-364.
SANTOS, C. M.; VERISSIMO, V.; WANDERLEY FILHO, H. C. L.; FERREIRA, V. M.; CAVAlCANTE, P. G. S.; ROLIM, E. V.; ENDRES, L. 2013. Seasonal variations of photosynthesis, gas exchange, quantum efficiency of photosystem II and biochemical responses of Jatropha curcas L. grown in semihumid and semiarid areas subject to water stress. Industrial Crops and Products, v. 41, p. 203-213.

STENBAEK, A.; JENSEN, P. E. 2010. Redox regulation of chlorophyll biosynthesis. Phytochemistry, v. 71, n. 8, p. 853-859.

STREIT, N. M.; CANTERLE, L. P.; CANTO, M. W.; HECKTHEUER, L. H. H. 2005. As clorofilas. Ciência Rural, v. 35, n. 3, p. 748-755.

TAIZ, L.; ZEIGER, E.; MOLLER, I. M.; MURPHY, A. 2017. Fisiologia e Desenvolvimento vegetal. Porto Alegre, Artmed, $6^{\mathrm{a}}$ edição.

TONIN, J.; MACHADO, J. T. M.; ROHRIG, B.; SOBUCKI, L.; RICHTER, A. F.; BETEMPS, D. L.; SCHMITT, O. J.; SCHNEIDER, E. P. 2016. Modelos lineares e não-lineares para determinação indireta de clorofila em folhas de morangueiro. Revista Interdisciplinar de Ensino, Pesquisa e Extensão, v. 3, n. 1, p. 216-223.

VON ELBE, J. H. 2000. Colorantes. In: Fennema O. W. (Ed.) Química de los alimentos. 2.ed. Zaragoza, Wisconsin-Madison., pp. 782-799. 